\title{
INCIDENCIA DE LA VARIABILIDAD HIDROLÓGICA EN LA MORFOLOGÍA DE CAUCES DEL ARROYO CLAROMECÓ (BUENOS AIRES, ARGENTINA)*
}

\author{
Belén García Martínez ${ }^{1}$, María Elizabeth Carbone ${ }^{2}$ \\ Cintia Píccolo² y Gerardo M. E. Perillo ${ }^{2}$ \\ (1) Dpto. Geografía Física y Análisis Geográfico Regional \\ Universidad de Sevilla \\ mbelen@us.es \\ (2) Instituto Argentino de Oceanografía. Consejo Nacional de Investigaciones \\ Científicas y Técnicas \\ Bahía Blanca (Argentina) \\ ecarbone@criba.edu.ar
}

\begin{abstract}
Resumen: En este trabajo se pone de manifiesto la variabilidad hidrológica del Arroyo Claromecó, así como la configuración morfológica de los cauces y las márgenes de su tramo principal y sus principales afluentes. Los resultados son entre otros, la designación de un régimen pluvial oceánico matizado, de escasa irregularidad y con un escaso coeficiente de escorrentía; y la detección de procesos de zapamiento, socavamiento e incisión fluvial en su tramo principal. Estos procesos están reactivados por la ejecución de encauzamientos y rectificaciones en la red fluvial del Claromecó.
\end{abstract}

Palabras claves: Hidrología, Hidromorfología, antropización, Arroyo Claromecó, Argentina.

\begin{abstract}
This paper focuses on the hydrological variability of the Claromecó Creek as well as on the morphology of both its courses and the banks of the main course and major affluents. The outcome of this research helped determine its rainfall pattern as oceanic- though with a very small irregularity and runoff rate- and detect the processes of excavation, subsidence and fluvial incision in the main course. These processes have been reactivated by the channelling and straightening of the Claromecó fluvial network.
\end{abstract}

Keywords: Hydrology, hydromorphology, anthropism, Claromecó Creek, Argentina.

* Recibido: 15-10-08. Aceptado: 30-12-08. 


\section{Introducción}

Los ríos constituyen, sin duda, los agentes más dinámicos que, en un sistema de proceso- respuesta, actúan sobre el dominio continental para escalas espaciales de cuencas vertientes. Por otra parte, el gran número de variables que afectan a la dinámica fluvial, así como los numerosos procesos que actúan no sólo sobre el cauce, sino también en las laderas de la cuenca, confieren a los ríos la complejidad de un sistema estructurado (Schumm and Lichty, 1965; Morisawa 1973).

Considerar, por tanto, la cuenca de drenaje como un sistema estructurado y abierto (Schumm, 1977) equivale a poner el acento sobre los ajustes e interrelaciones entre procesos y formas, sobre el carácter multivariado de los fenómenos geomorfológicos y sobre el medio físico integral de la cuenca, incluyendo las intervenciones antrópicas (Gregory and Walling, 1973). De esta manera, la respuesta de un río a las modificaciones que experimenta su entorno ya sea de tipo climático, hidrológico, antrópico, o de cualquier otra índole, supone una ruptura en el equilibrio entre caudal y carga sólida transportada (Schumm, 1977), quedando registrada tanto a nivel de morfología de su cauce como de morfología y sedimentología de su llanura aluvial.

Concretamente, la morfogología del cauce ordinario está sujeta a la capacidad morfogenética del flujo en bankfull o de cauce ordinario lleno (Wiliams, 1978). Esta capacidad morfogética se vincula a la aceleración que experimenta el flujo como consecuencia del incremento del radio hidráulico, según se desprende de la ecuación de Chézy, lo que determina que en bankfull se maximice la capacidad de transporte de sedimentos, tal y como apunta Carling (1988).

El término bankfull y sobre todo, el método para su identificación han sido aspectos recurrentes en la literatura científica; por lo que numerosos autores han abordado su definición desde perspectivas diferentes aunque complementarias. Así, Wolman y Leopold (1957) definen el estado bankfull como la elevación de la planicie de inundación activa; Henderson (1961) como la marca del inicio de una incipiente inundación; mientras que Schumm (1960) y Williams (1978) lo describe, en términos de vegetación, como la altura del límite inferior de la vegetación de porte arbóreo. Con todo ello, los indicadores que determinan la anchura de bankfull en la llanura serán, precisamente, la morfología de la llanura de inundación, la morfología y composión de las márgenes y la vegetación (Pleus y Schett-Hames, 1998).

\section{Objetivos y área de estudio}

El objetivo principal de este trabajo es profundizar en el estudio hidrológico del arroyo Claromecó, para el periodo húmedo 1999-2002; con el propósito de analizar la incidencia de su variabilidad en la configuración morfológica de cauces y márgenes. Para ello se hará especial hincapié en la descripción de los elementos de su régi- 
men fluvial y su manifestación en la llanura aluvial. Asimismo, se identificarán las principales actuaciones antrópicas que infieren cambios en la dinámica natural del arroyo, y en la morfología de sus cauces.

El arroyo Claromecó se encuentra localizado al Sudeste de la provincia de Buenos Aires, en la región pampeana húmeda (figura 1). Nace en las lagunas de los partidos vecinos al de Tres Arroyos, en la denominada Pampa de Juárez o llanura interpuesta, entre los sistemas serranos de Ventania y Tandilia. Este arroyo, de 59,5 km de longitud, se forma a partir de la confluencia de tres cursos de agua, aguas abajo de la ciudad de Tres Arroyos: el arroyo Seco o Tercer Brazo de los Tres Arroyos (77,6 $\mathrm{km})$, al oeste; el Arroyo del Medio o Segundo Brazo (61 km), en el centro; y el Arroyo Orellano o Primer Brazo $(24 \mathrm{~km})$, al este. Su trazado se encuentra parcialmente antropizado a raíz del riesgo que supone, para la ciudad, la red fluvial del Claromecó en periodos de aguas altas. Así, para evitar el desbordamiento de los tres brazos y del propio Claromecó se canalizan sus trazados, urbanos y suburbanos en la década de los ochenta definiendo sus taludes, y dotándoles de un mayor calado mediante obras de profundización y ampliación de cauces.

En su recorrido desarrolla una cuenca de drenaje de 3.017,18 $\mathrm{km}^{2}$ de extensión, hasta su desembocadura en el océano Atlántico. Topográficamente está caracterizada por un paisaje de escasa pendiente $(<3,5 \%)$; tan sólo interrumpido por el ambiente de Lomadas al Norte, que dan a la cuenca alta una topografía sumamente ondulada (pendientes medias entre 5 y 10\% Carbone et al., 2006). En ella destacan abundantes cuerpos lagunares, de fondo plano, con límites definidos y de régimen permanente; que aún no están integradas en la red fluvial.

La vegetación predominante es la estepa o seudoestepa de gramíneas del género Stipa (Stipa neesiana o Stipa papposa); los arbustos están representados por las brusquillas (Cassia tora L.), y entre las hierbas hay verbenas del género Glandularia, entre otras. Por otra parte, en las orillas de los arroyos la vegetación hidrófila natural son cortaderas (Cortaderia selloana) y sauce criollo (Salix Humboltiana). La buena cobertura de vegetación herbácea existente en la cuenca del arroyo Claromecó, protege las vertientes mayores de la erosión hídrica y favorece la infiltración (Carbone, 2004). Este hecho, determina una importante recarga de los acuíferos, los cuales vierten sus excedentes a cauces regionales durante la época de estiaje.

Considerando las características de los suelos dominantes, esto es, Argiacuoles, Argiudoles y Argiudoles típicos, en la cuenca alta, media y baja respectivamente, el uso de las tierras de esta región es eminentemente agrícola y agrícola-ganadera, en la mayor parte de su extensión. Las áreas ganaderas se limitan a los sectores con problemas de hidromorfismo y alcalinidad, que ocupan las superficies subordinadas (Carbone, 2004).

Por tanto, cabe destacar que aunque el arroyo Claromecó no es uno de los cursos principales de la provincia, se encuentra en una región que desempeña un papel preponderante en la economía del país, gracias a la importancia que tienen las actividades agrícolas-ganaderas (Carbone y Píccolo, 2002). 

Cintia Píccolo y Gerardo M. E. Perillo

Figura 1. Localización de la cuenca del Arroyo Claromecó y secciones fluviales muestreadas.

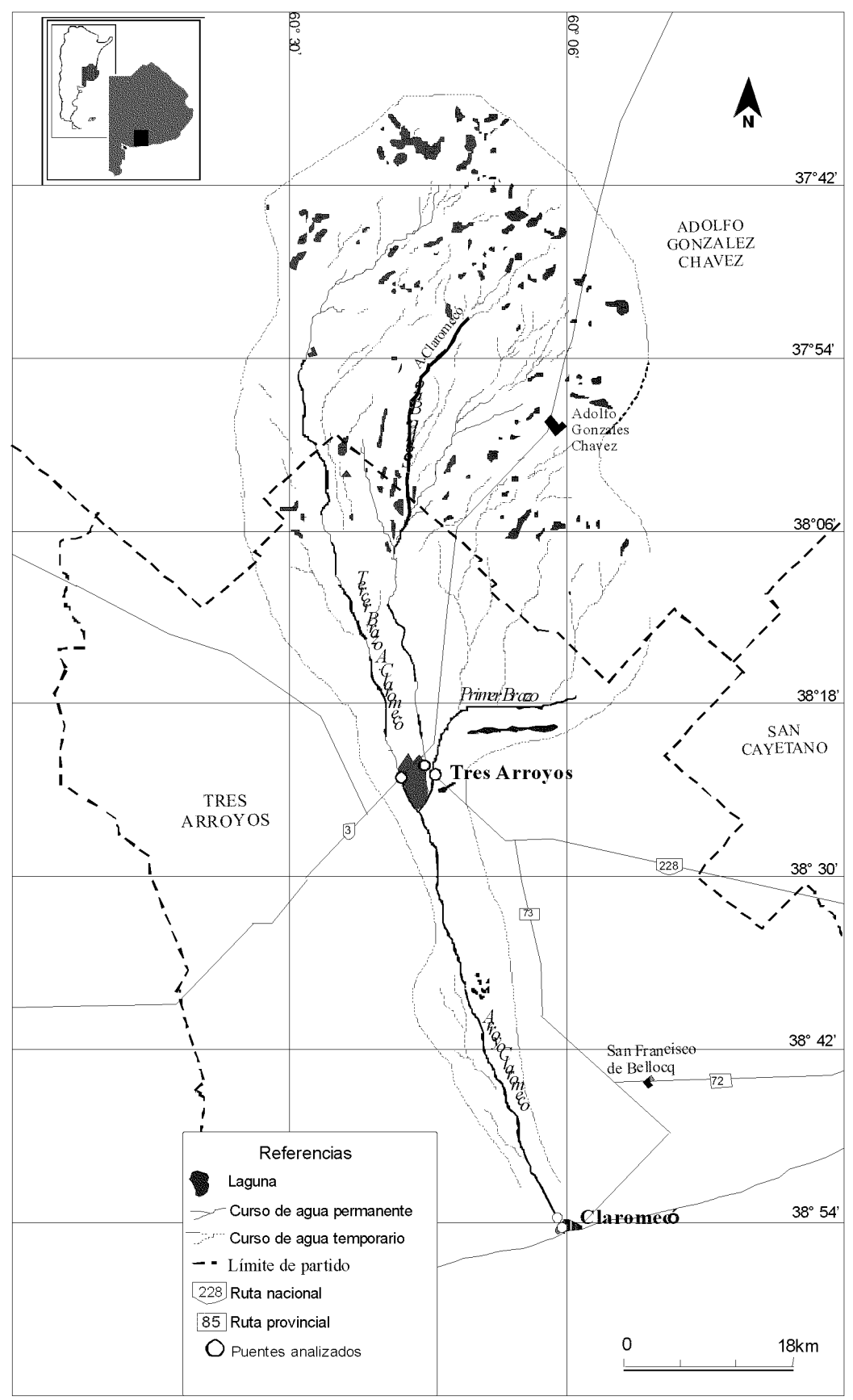




\section{Metodología}

La ausencia de estaciones de aforo de la Red Hidrológica Nacional Argentina en la cuenca del arroyo Claromecó determina que los datos con los que contamos para el análisis hidrológico sean aquéllos obtenidos en estudios previos (Carbone, 2004). La instalación de un limnígrafo en el cauce principal, aguas abajo de la confluencia de los tres brazos, ha permitido contar con un registro de caudal de cuatro años (1999-2002).

Hasta el momento, estos datos han sido tratados en trabajos anteriores (Carbone, 2004; Carbone et $a l$, 2006) de forma independiente para cada año; utilizando para ello los valores medios mensuales de caudales.

En este trabajo se pretende analizar la variabilidad hidrológica del arroyo Claromecó desde una perspectiva global. Con ello se han analizado los elementos que definen el régimen fluvial (módulo, coeficiente de irregularidad y variabilidad estacional, mediante valores tipificados) y el comportamiento hidrológico de su cuenca (caudal específico, aportación, aportación específica y coeficiente de escorrentía).

Sin embargo, y bajo la premisa que una serie de cuatro años no es representativa para definir un modelo de comportamiento fluvial, se procede a la aplicación en forma de ensayo, de algunos modelos que estiman la escorrentía a partir de valores de precipitación. Teniendo en cuenta que se trata de una cuenca de tamaño mediano (Carbone et $a l, 2006$ ) y de características homogéneas, y que la escala de tiempo considerada es la apropiada (Vélez y Vélez, 2002, cfr. Shaw, 1994), se aplican dos de los modelos más simples y más utilizados: los modelos de Grunsky y Turc. Sin embargo, entendemos que la aplicación de este tipo de fórmulas empíricas ha de realizarse con sumo cuidado, ya que en la mayoría de los casos estas fórmulas han sido deducidas para condiciones climáticas específicas; por lo que los resultados obtenidos han de considerarse una primera aproximación.

Según el modelo Grunsky, la pérdida E (transpiración y evaporación) se establece por medio de un rango que se expresa como $\left(0,4^{*} \mathrm{P}\right)$ y $(\mathrm{P}-\mathrm{E}$ máximo), para precipitaciones menores y mayores a 1,25 metros respectivamente, y determina que las escorrentías se pueden estimar como:

$$
Q=\left(\left(0,4 * P^{2}\right) * S\right) / 31536000 \quad \text { para } P \leq 1,25 m
$$

Donde Q es la escorrentía media anual sobre la cuenca expresada en $\mathrm{m}^{3} / \mathrm{s}, \mathrm{P}$ precipitación sobre la cuenca, expresada en metros, S superficie de la cuenca, expresada en $\mathrm{m}^{2}$ y E, pérdida por transpiración y evaporación $\left(\mathrm{m} / \mathrm{m}^{2}\right)$.

Por su parte, el modelo de Turc fue obtenido a partir de observaciones efectuadas en 254 cuencas de climas diferentes de distintos países del mundo (Sandoval, 2000 cfr, López, 1998). Las pérdidas expresadas por E, son determinadas a través de la temperatura y la precipitación. La escorrentía es estimada a través de la expresión:

$$
Q=((P-E) * S) / 31536000
$$



Cintia Píccolo y Gerardo M. E. Perillo

Donde: $\mathrm{E}=\left(\mathrm{P} /\left(0.9+(\mathrm{P} / \mathrm{L})^{2}\right)^{0.5}\right) / 1000 ; \mathrm{L}=300+25 * \mathrm{~T}+0.05 * \mathrm{~T}^{3} ; \mathrm{T}=$ temperatura media anual en ${ }^{\circ} \mathrm{C} ; \mathrm{P}=$ precipitación media en metros.

Con esta fórmula, los valores de caudal pueden verse alterados por las características excepcionales de la cuenca, a saber: cuencas de escasas dimensiones, de alta montaña, de fuerte o débil insolación, etc. (Sandoval, 2000; cfr. Benítez, 1998).

Trabajos recientes en Chile, concretamente en los ríos Achibueno y Purapel (Sandoval, 2000) y río Malleco (Sánchez, 2001) han utilizado estos modelos para la estimación del caudal medio anual de la cuenca; arrojando buenos resultados de adaptación del modelo de Grunsky en aquellas cuencas con un régimen de alimentación pluvial. Así mismo, el modelo de Turc es el utilizado, actualmente, por la Dirección General de Aguas en la zona centro y sur de Chile.

Para completar la información hidrológica e hidrogeomorfológica se efectúan varias campañas a la cuenca del arroyo Claromecó (figura 1), al cauce principal, aguas abajo de la confluencia de los tres brazos, y a sus tres principales afluentes (Primer, Segundo y Tercer Brazo). Durante las mismas se realizó el levantamiento de secciones transversales de cauces y márgenes; en las cuales, quedan plasmadas no sólo la morfología de lechos y barrancas de cada arroyo, sino también los distintos niveles hidrológicos en la llanura, esto es, caudal ordinario, bankfull y caudal de crecida. Estos niveles son perfectamente reconocibles no sólo en la llanura (morfología del cauce, vegetación, restos de ramaje, etc.); sino también en los puentes (distintos niveles de humedad). Así mismo, se identifican las actuaciones antrópicas acometidas en cauces y riberas, por su influencia en la estabilidad de las barrancas. Por último, se definen los procesos geomórficos predominantes en cada sector.

Por otro lado, el análisis hidrológico de la cuenca se completa con la realización del balance hídrico según el método de Thornthwaite-Matter (Pagney, 1982), en su aplicación al estudio de la ecodinámica del medio físico. En este caso, el balance parte de tres supuestos: a) la profundidad del suelo, donde tienen lugar las pérdidas de agua por evapotranspiración, viene definida por el sistema radicular de la vegetación. Estas pérdidas se convierten en potenciales acumuladas (Ppa) en el transcurso de los meses secos. El déficit de humedad (Dh), queda definido como la diferencia entre ETP y ETR; b) La capacidad de almacenamiento de agua en el suelo (St), susceptible de evapotranspirarse, está definida por la capacidad de campo (CC). El exceso de humedad (Eh) sólo aparece cuando P- ETP > 0, de tal manera que queda definida por la diferencia positiva de P- (ETP + (ØST)); c) Si el exceso de humedad es superior a la capacidad de campo, aquél percola hacia el acuífero, de manera que siempre y cuando exista excedente (Eh), de manera general, la escorrentía (R) será igual al excedente.

En la cuenca del Claromecó, este balance se realiza para una textura francolimosa, típica de los suelos Argiudoles, de claro predominio en la cuenca; y en los que prevalece el monocultivo del cereal. Se parte así, de una capacidad de campo de $200 \mathrm{~mm}$. Los datos meteorológicos utilizados son los aportados por la estación de 
Tres Arroyos para la serie húmeda analizada, esto es, la comprendida entre los años 1999-2002 y para la serie seca de comienzos de siglo (1908-1913). Se define así, el comportamiento hídrico del suelo para dos etapas bien diferenciadas.

\section{Resultados}

\subsection{Estimación teórica de caudales: relación precipitación-caudal}

La ausencia de estaciones de aforo, por un lado, y la escasez de datos directos de caudal, por otro, nos empuja a llevar a cabo un ensayo en la estimación de caudales teóricos del Arroyo Claromecó. Esta estimación teórica se realiza a partir de los datos de precipitación y temperatura aportados por la estación meteorológica de la ciudad de Tres Arroyos.

Para ello, se han utilizado los modelos de Grunsky y Turc, ampliamente utilizados en distintas cuencas del mundo (Sandoval, 2000, cfr. López, 1998). Sin embargo, la aplicación de dichos modelos, en la cuenca de estudio (tabla 1 y 2 ), parece no aportar valores de caudales que puedan correlacionarse con los obtenidos por medición directa, a través de limnígrafo. En ese sentido, coeficientes de Pearson próximos a cero entre el caudal estimado y el real, en la aplicación de ambos modelos, refleja la inexistencia de una relación lineal entre ambas variables y por tanto, un mal ajuste

Tabla 1.

\begin{tabular}{cccc}
\hline & $P(m)$ & $\begin{array}{c}\text { Teórico } \\
\left(\mathrm{m}^{3} / \mathrm{s}\right)\end{array}$ & $\begin{array}{c}\text { Aforado } \\
\left(\mathrm{m}^{3} / \mathrm{s}\right)\end{array}$ \\
\hline 1999 & 0,6625 & 16,8 & 1,2 \\
2000 & 0,8511 & 27,7 & 0,6 \\
2001 & 1,1716 & 52,5 & 1,0 \\
2002 & 1,0159 & 39,5 & 1,0 \\
\hline
\end{tabular}

Tabla 2.

\begin{tabular}{ccccc}
\hline & $P(m)$ & $T\left({ }^{\circ} \mathrm{C}\right)$ & $\begin{array}{c}\text { Teórico } \\
\left(\mathrm{m}^{3} / \mathrm{s}\right)\end{array}$ & $\begin{array}{c}\text { Aforado } \\
\mathrm{m}^{3} / \mathrm{s}\end{array}$ \\
\hline 1999 & 0,6625 & 14,5 & 63,3 & 1,2 \\
2000 & 0,8511 & 14,1 & 81,4 & 0,6 \\
2001 & 1,1716 & 14,8 & 112,1 & 1,0 \\
2002 & 1,0159 & 14,6 & 97,2 & 1,0 \\
\hline
\end{tabular}



Cintia Píccolo y Gerardo M. E. Perillo

entre ellas. Sin embargo, la buena correlación existente (C.P: 0.99) entre los datos teóricos de caudal estimados mediante las dos ecuaciones (figura 2), sí que señala al menos, un mismo rango de desviación de los datos estimados (ya sea a través de la ecuación de Grunsky o la de Turc), respecto a los datos reales, medidos con el limnígrafo. En definitiva, los valores de caudales teóricos distan bastante de los datos de caudal aforados en la cuenca del arroyo Claromecó.

Este contraste entre caudales teóricos y caudales aforados, en una cuenca de llanura como la del arroyo Claromecó, caracterizada por una escasa pendiente topográfica y un complicado drenaje superficial; infiere la existencia de pérdidas de agua, probablemente por infiltración y percolación. Todo parece indicar que, buena parte del agua que entra en el sistema del Claromecó no sale por la vía del escurrimiento superficial. Por tanto, se desestima la aplicación de estos dos modelos en la obtención de caudales teóricos a partir de las precipitaciones.

Por otro lado, si atendemos con mayor precisión la relación existente entre la variable precipitación y el caudal para el periodo aforado (figura 3), se observa igualmente, un desfase de varios meses entre la precipitación y la escorrentía superficial en la cuenca del arroyo Claromecó y por tanto, una débil correlación entre ambos parámetros (C. Pearson de 0,38).

Tal y como puede verse en la figura 3 la variabilidad estacional de los caudales responde a la estacionalidad de las precipitaciones, aún cuando se detecta un cierto desfase temporal entre ambos. Así, el máximo de precipitaciones de marzo y las lluvias de abril van a determinar el incremento de caudal hasta niveles del 50\%, aún cuando sin llegar a superar su valor modular, en los meses de abril y de mayo. La recarga hídrica que supone las lluvias de los meses de otoño, implica que el arroyo

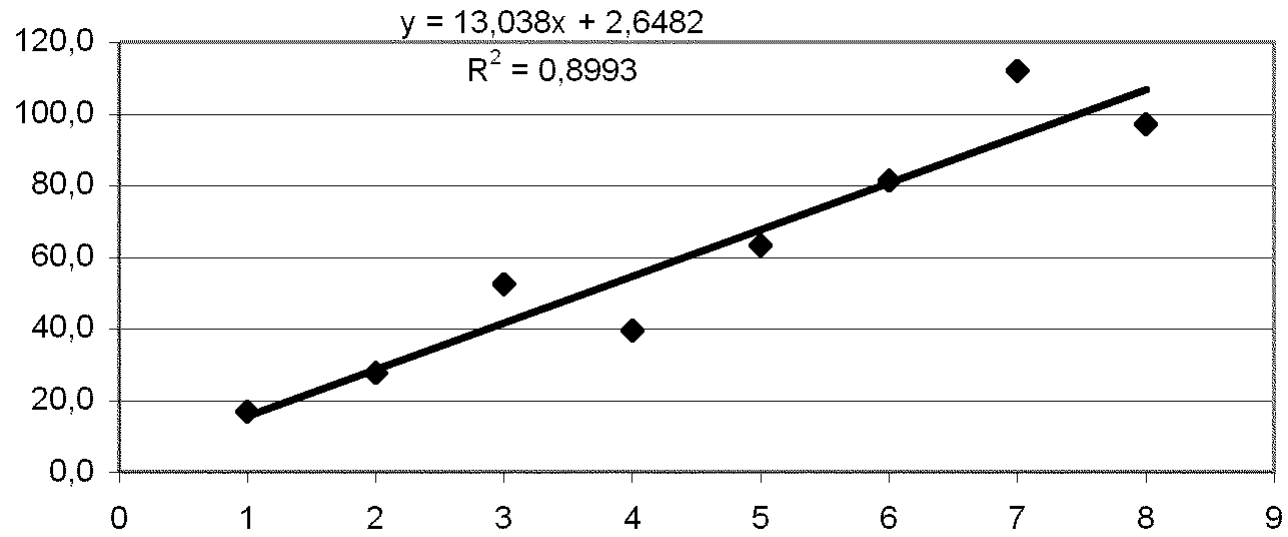

Figura 2. Relación entre los valores estimados por los modelos de Grunsky y Turc para el periodo analizado (1999-2002). 


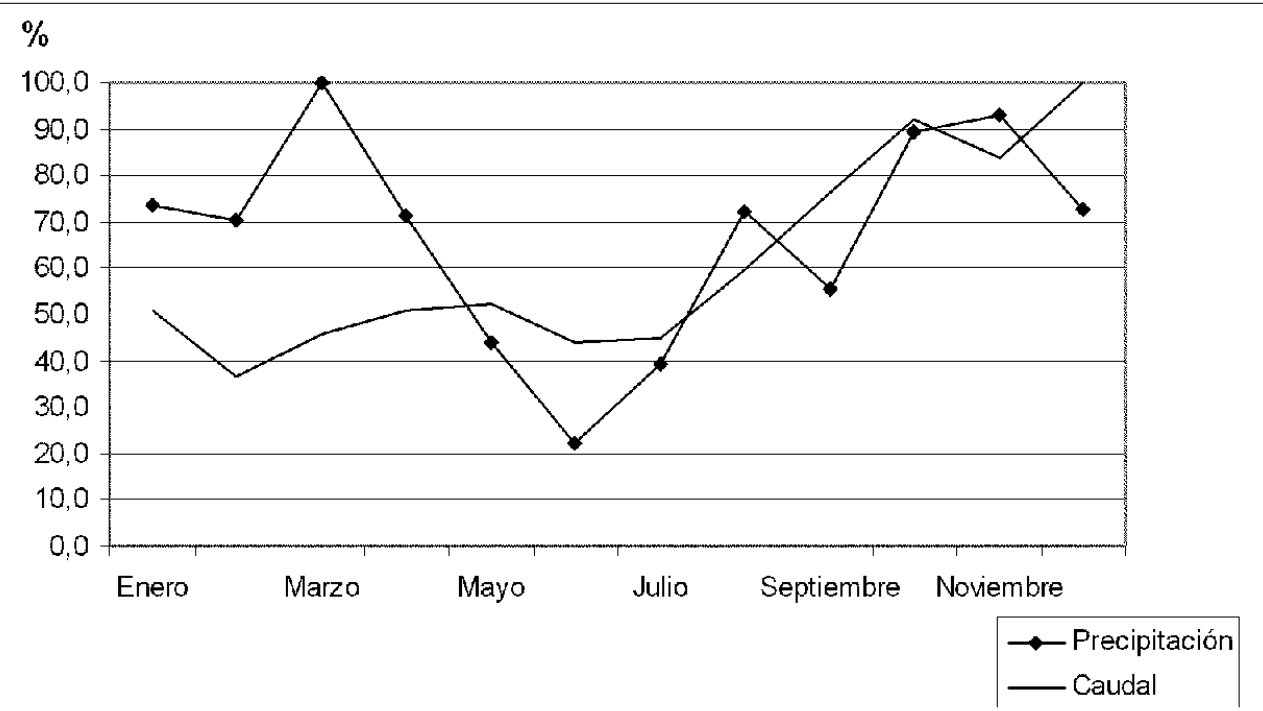

Figura 3. Comparación entre la variabilidad estacional de la precipitación y el hidrograma característico adimensional del arroyo Claromecó para la serie 1999-2002.

Claromecó mantenga los niveles de caudales en torno al 45\% hasta el mes de julio, sin afectarle el descenso brusco de lluvias detectado en el mes de febrero. A partir de entonces, y asociado a un incremento generalizado de las precipitaciones desde agosto hasta noviembre, el caudal del arroyo ve incrementado su caudal paulatinamente hasta su máximo en el mes de diciembre. Así mismo, el hecho de que estemos en un periodo húmedo hace posible que el estiaje suponga tan sólo un descenso leve por debajo de su valor modular, pero manteniendo cerca del $40 \%$ de su caudal. De ello se desprende una curva de caudal que regula o suaviza la estacionalidad de la precipitación con un desplazamiento de varios meses respecto a ella.

\subsection{Variabilidad hidrológica de la cuenca del Claromecó}

Aún cuando la serie de caudales del arroyo Claromecó no es representativa para la definición de su régimen fluvial, el estudio de la curva de coeficientes de caudal y de su hidrograma característico adimensional puede arrojar algunas consideraciones al respecto.

Para estos años, la curva de coeficientes de caudal del arroyo Claromecó pone de manifiesto una variabilidad hidrológica, englobada, en lo que Pardé (1955) definió como Pluvial Oceánico; tal y como se expone en trabajos anteriores (Carbone, 2004; 

Cintia Píccolo y Gerardo M. E. Perillo

Carbone et al., 2006). Sin embargo, se detectan ciertas matizaciones, que expondremos a continuación, y que bien pudieran deberse a los escasos datos con los que se cuenta, o a ciertas particularidades de la cuenca. Su comportamiento está caracterizado por un solo máximo, desde octubre a diciembre, cuyo punto más álgido se da en diciembre, con un coeficiente de 1,6 (figura 4). Y un mínimo poco acusado, desde enero a septiembre, con valores de coeficientes de 0,6; aunque con una ligera recuperación de la curva en los meses de abril y mayo, sin llegar a superar el valor modular. Este comportamiento peculiar, algo alejado de la variabilidad estacional que describió Pardé (1955) para un régimen pluvial oceánico, tiene su explicación por un lado, en la existencia de un caudal de base procedente del acuífero que le aporta hasta un 36\% al caudal fluvial (Carbone et al., 2006) y por otro, en la presencia de pendientes poco pronunciadas y numerosas lagunas en la cuenca alta.

Otra característica de este río de llanura radica en la escasa irregularidad estacional. Así se manifiesta en la escasa varianza existente entre el comportamiento del mes menos caudaloso $\left(0,60 \mathrm{~m}^{3} / \mathrm{s}\right)$ y del mes más caudaloso $\left(1,6 \mathrm{~m}^{3} / \mathrm{s}\right)$, en el periodo analizado. Ello supone una irregularidad media del $37 \%$.

Por otro lado, el comportamiento hidrológico de la cuenca (figura 5) está definido por una entrada al sistema de $886,8 \mathrm{~mm}$, que genera un escaso módulo, una débil irregularidad estacional, valores de aportes y de caudal específico modestos y un pequeño coeficiente de escorrentía. Una vez más, los datos reflejan la existencia de importantes pérdidas de agua, bien por colmatación de lagunas, bien por infiltración y percolación.

$\mathrm{Cq}$

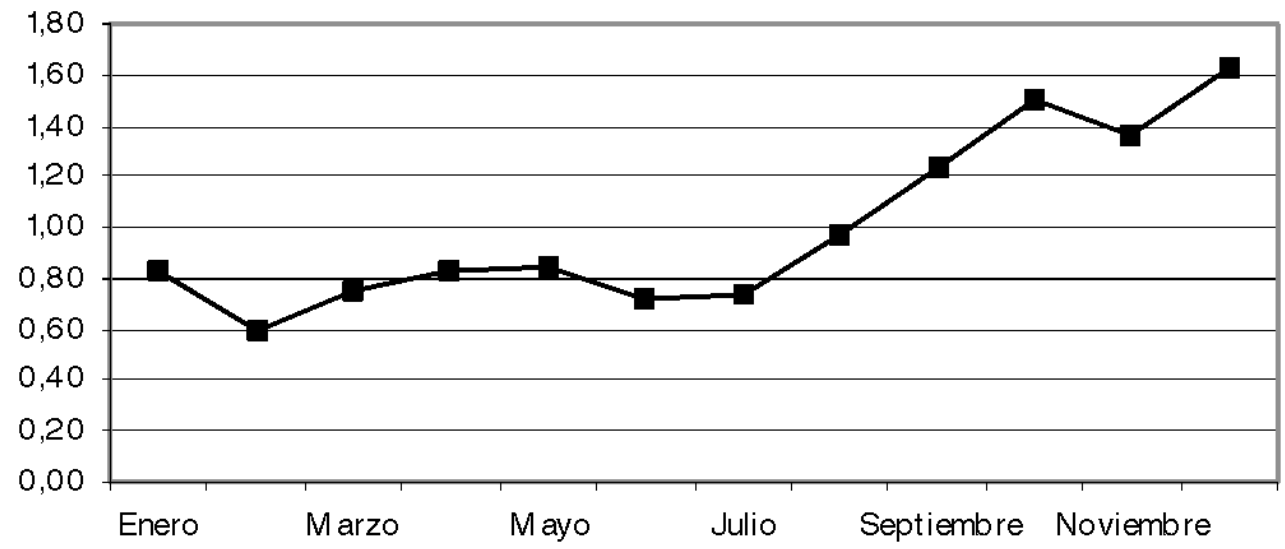

Figura 4. Comportamiento estacional del arroyo Claromecó (1999-2002). 


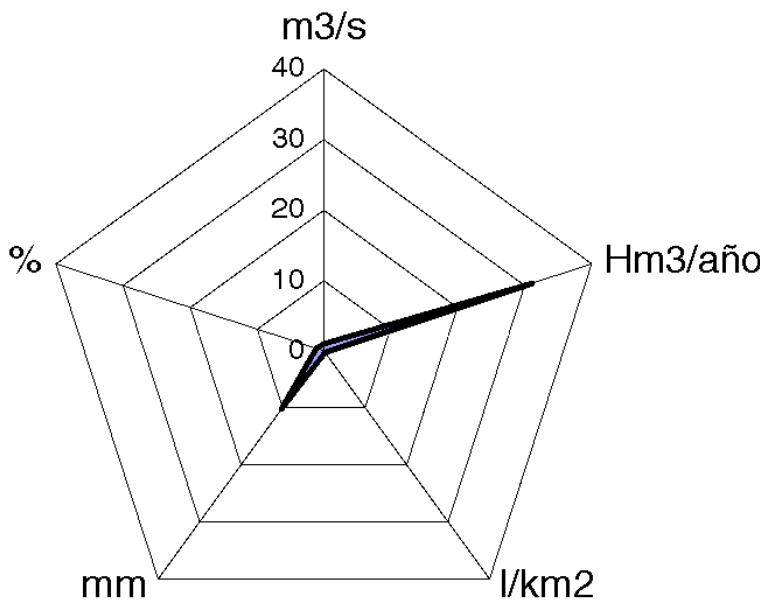

\begin{tabular}{|c|r|}
\hline P media & $886,82 \mathrm{~mm}$ \\
$\mathrm{Q}_{\mathrm{ma}}$ & $0,9 \mathrm{~m}^{3} / \mathrm{s}$ \\
$\mathrm{A}$ & $31,1 \mathrm{Hm}^{3} /$ año \\
$\mathrm{q}$ & $0,33 \mathrm{l} / \mathrm{km}^{2}$ \\
$\mathrm{~L}$ & $10,27 \mathrm{~mm}$ \\
$\mathrm{e}$ & $1,16 \%$ \\
\hline
\end{tabular}

Figura 5. Comportamiento hidrológico de la cuenca del arroyo Claromecó para el periodo 1999-2002.

\subsection{Balance hídrico de la cuenca del Claromecó}

La realización del balance hídrico para dos periodos diferentes, uno seco y otro húmedo, al comienzo y final del siglo XX respectivamente; permite definir, de una manera más completa, el comportamiento hídrico del suelo.

El correspondiente al periodo húmedo, inicia el año hidrológico en el mes de marzo (figura 6). Éste sería el primer mes en el que la precipitación es superior a la evapotranspiración potencial, tras un periodo de déficit hídrico. A partir de entonces, el comportamiento del suelo inicia su recarga de humedad hasta alcanzar la saturación del suelo en el mes de agosto. A lo largo de estos cinco meses de recarga, son los meses de abril y julio, en los que existe un mayor incremento del agua capilar contenida en el suelo (33 y $36 \mathrm{~mm}$ respectivamente).

Tras este periodo, el suelo alcanza su capacidad de campo (200 mm) y con ello se inicia un periodo de escorrentía superficial de cuatro meses, que abarca desde el mes de agosto hasta el mes de noviembre. La máxima escorrentía se concentra en el mes de octubre con un valor medio superior a $100 \mathrm{~mm}$.

A partir de entonces, el balance hídrico refleja un periodo de déficit de cuatro meses, que iría desde diciembre hasta febrero, correspondiendo con la época estival. En estos meses, el suelo gasta progresivamente su reserva hídrica, sin llegar en ningún caso a quedarse completamente seco, a pesar de los altos valores de evapotranspiración real. A decir verdad, el balance refleja un remanente medio de $104 \mathrm{~mm}$, esto es, más del 50\% de lo que le permite su capacidad de campo. 


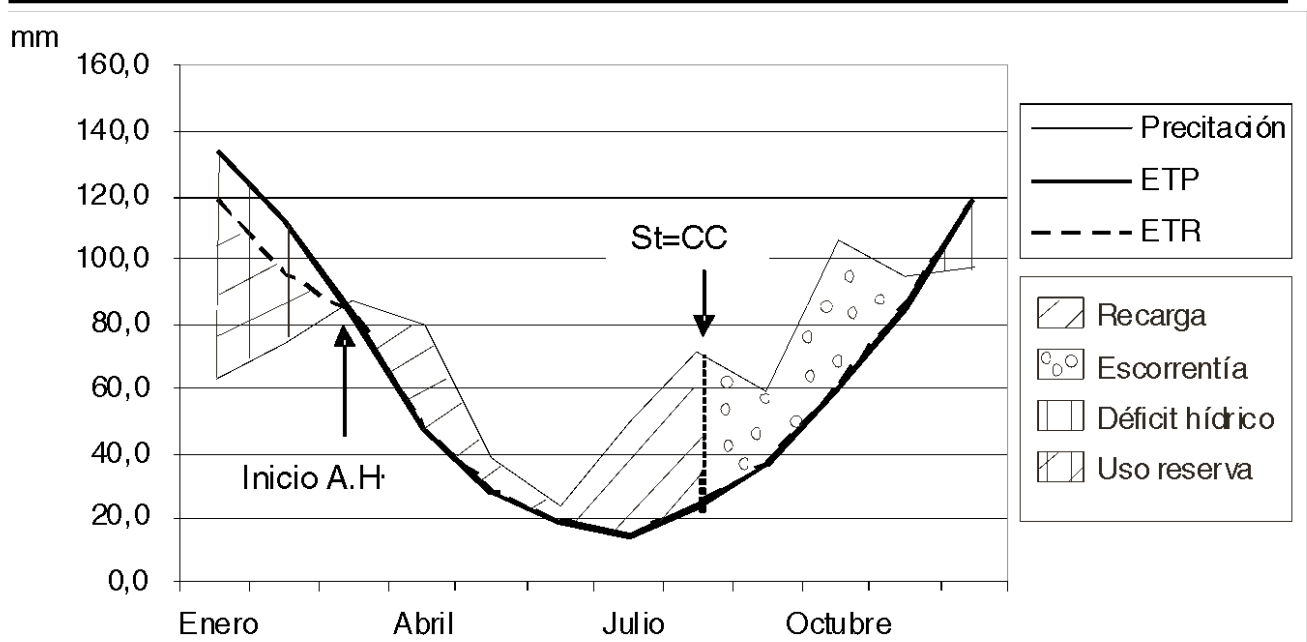

Figura 6. Balance hídrico de la cuenca media del arroyo Claromecó en periodo húmedo (1999-2002).

La situación difiere de la anterior, en el caso de una serie de años con niveles de precipitación anuales por debajo de $590 \mathrm{~mm}$. Este nivel de precipitaciones es el límite superior del rango de años definidos como muy secos, según el estudio de los quintiles de la serie de Tres Arroyos en el periodo 1905-2000. En este caso, tal y como puede observarse en la gráfica correspondiente (figura 7), el comienzo del año hidro-

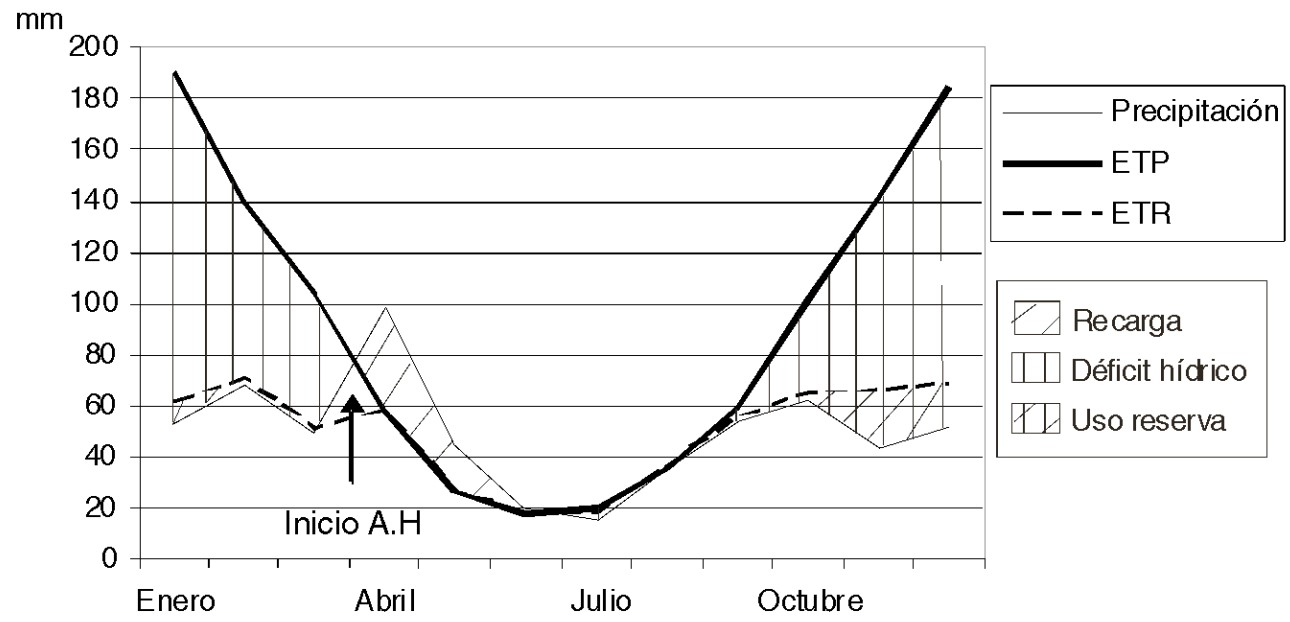

Figura 7. Balance hídrico de la cuenca media del arroyo Claromecó en periodo seco (1908-1911). 
lógico se traslada al mes de abril, a partir del cual se inicia un periodo de recarga hídrica del suelo que se amplia hasta el mes de junio. Este periodo de recarga supone una reserva hídrica en el suelo de tan sólo $75 \mathrm{~mm}$; un valor muy por debajo del que le marca su capacidad de campo $(200 \mathrm{~mm})$. En estas condiciones, hay que entender que el suelo no alcance su saturación y por consiguiente no propicie la escorrentía superficial. Por otro lado, se identifica un largo periodo de déficit hídrico de 9 meses, en el que el suelo pierde prácticamente toda el agua, como consecuencia de las altas temperaturas y la escasa reserva acumulada en el suelo.

\subsection{Características morfológicas de los cauces en el Arroyo Claromecó}

Para llevar a cabo el análisis hidromorfológico del arroyo Claromecó, se analizan cuatro secciones transversales localizadas en distintos puntos de su red fluvial (figura 1): a la altura del puente de la ruta nacional 3, en el Tercer Brazo; en los puentes de la ruta nacional 228 al cruzar el Primer y Segundo Brazo y en el tramo principal del Claromecó, a la altura del puente peatonal y del camino carretero. Para la selección de dichas transversales ha sido imprescindible la presencia de puentes con estructura en pilas; de tal manera que el puente no sólo va a ser un elemento más de control en el análisis hidrológico de los arroyos (niveles de humedad), sino que además podrá arrojar valiosa información sobre la dinámica (socavamientos y/o zapamientos) predominante en los sectores analizados.

En estas transversales se estudian todos aquellos aspectos de interés referente, tanto a nivel hidromorfológico, como de transformación antrópica de sus cauces y riberas: el cauce y sus márgenes (transformados o naturales), la vegetación (degradada o natural), la infraestructura que acoge dicho espacio (carreteras, ferrocarriles, puentes, canales), así como los niveles hidrológicos en la llanura (caudal ordinario, crecida ordinaria o bankfull y crecida extraordinaria).

La sección fluvial estudiada para el Arroyo Orellano (figura 8), en las inmediaciones de la localidad de Tres Arroyos, está definida por un cauce de, aproximadamente, $12 \mathrm{~m}$ de ancho. Morfológicamente, éste presenta un fondo plano, tan sólo interrumpido por la presencia de bloques externos al lecho; y taludes más o menos verticalizados que alcanzan entre 1 y 1,6 m de altura. Sus márgenes desprovistas de cualquier tipo de vegetación natural, presentan evidentes signos de inestabilidad, en las que se detecta una progresión de cárcavas. La vegetación natural, fundamentalmente juncos, se ubica estrictamente en el lecho ordinario, mientras que las márgenes acogen especies introducidas, como es el caso del eucalipto.

La variabilidad hidrológica en esta sección fluvial, queda representada por las distintas alturas que alcanza la lámina de agua como, caudal ordinario, bankfull y en avenida extraordinaria. En este sentido, el nivel de bankfull o nivel de cauce ordinario, queda definido, originalmente en la zona, en algo menos de $1 \mathrm{~m}$, infiriendo posibles desbordes a partir de dicha altura. Sin embargo, y como consecuencia de la cana- 

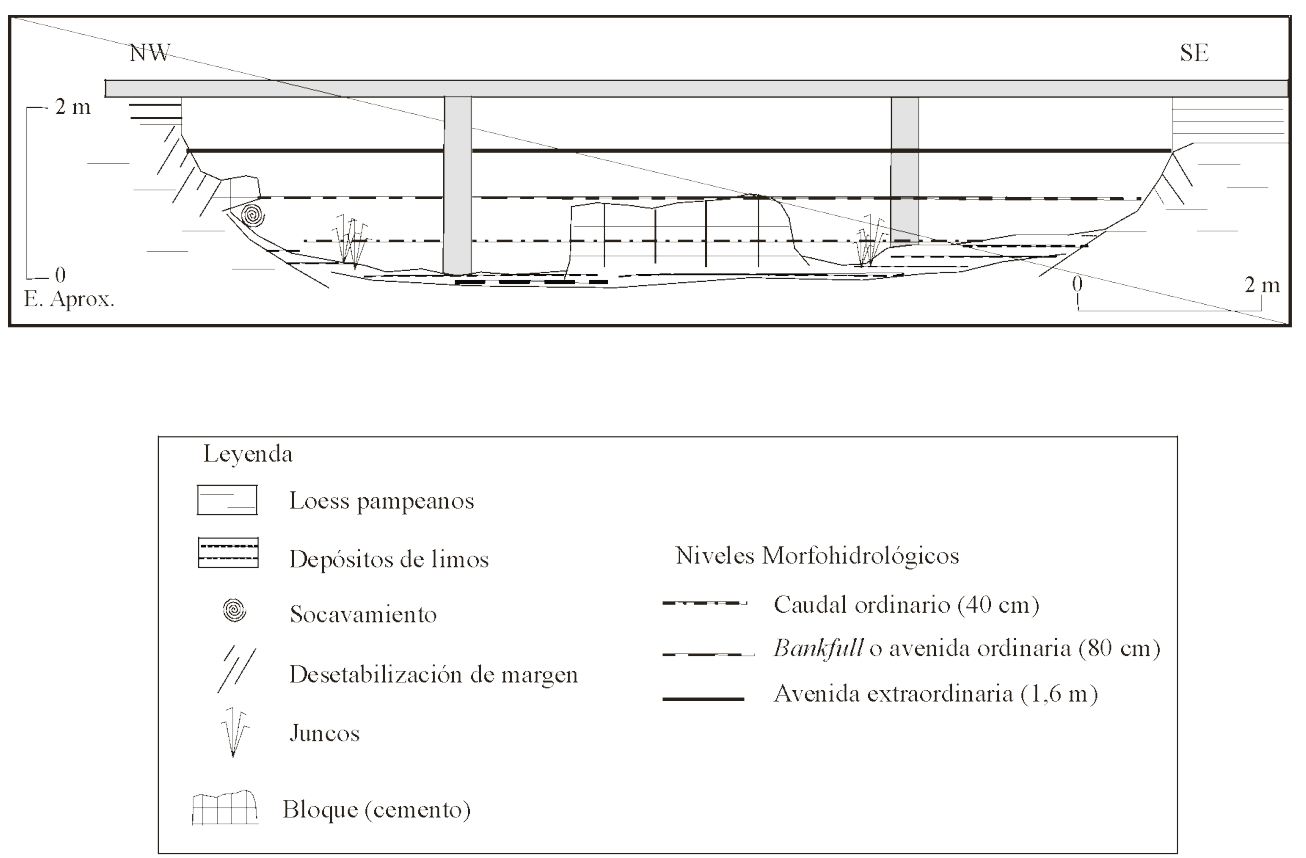

Figura 8. Transversal hidrogeomorfológica del Arroyo Orellano en la ruta nacional 228.

lización llevada a cabo en todo el tramo suburbano del Arroyo Orellano, las márgenes están sobreelevadas, y las avenidas extraordinarias, medidas hasta el momento en 1,6 m, tan sólo supondrán desbordamientos locales y esporádicos.

El balance energético del flujo, en rango de bankfull, implica una débil colmatación general de finos en el lecho; así como procesos de zapamiento lateral, en la margen izquierda. En este caso, el zapamiento parece estar asociado a la turbulencia que engendra el incremento de caudal, dentro del límite de cauce ordinario, reactivada sin duda, por la propia rugosidad del lecho (bloques). En este caso, la dirección del flujo se desplaza hacia la margen izquierda, donde se localiza el punto de máximo ataque erosivo local, desestabilizando, por tanto, dicha margen.

En el Segundo Brazo no se ha llevado a cabo el levantamiento de la transversal hidromorfológica, puesto que el cauce en este sector se encuentra totalmente antropizado y su morfología no responde, por tanto, a condiciones morfogenéticas naturales. El arroyo del Medio es el que más problemas de inundación ha generado en la ciudad de Tres Arroyos, y por tanto, al que más actuaciones se le acometen. En este sentido, el cauce ha sido ampliado y profundizado para dotarle de un mayor calado en la evacuación de la máxima crecida. De esta manera, el cauce alcanza un ancho en la zona de aproximadamente $19 \mathrm{~m}$. Sus taludes, con $22 \mathrm{~m}$ lineales de hormigón 
armado, forman un muro de $30 \mathrm{~cm}$ en su parte superior y 40 en su base, apoyado en una planta de hormigón armado de $30 \mathrm{~cm}$ de espesor. Todo construido sobre la contrapesa de hormigón de piedra por debajo del nivel del agua. La altura del muro es de $2 \mathrm{~m}$ y presenta refuerzos transversales cada $3 \mathrm{~m}$, con puntales hincados coincidentemente.

Sin embargo, y gracias a la ubicación del puente, anterior a los trabajos de canalización del arroyo, se ha podido identificar los distintos niveles hidrológicos, que ratifican las medidas tomadas en el arroyo Orellano, en un nivel de antropización inferior: el nivel de caudal ordinario está a $20 \mathrm{~cm}$, el nivel de bankfull a $80 \mathrm{~cm}$ y el caudal de crecida extraordinaria a $1,7 \mathrm{~m}$.

La sección fluvial analizada en el Tercer Brazo (figura 9), refleja un trazado seminatural de naturaleza sinuosa. Ésta está definida por un cauce ordinario de algo más de $4 \mathrm{~m}$ de anchura y taludes verticales de aproximadamente un $1 \mathrm{~m}$. Por encima de este nivel, se abre la llanura de inundación, ocupada por el flujo tan sólo en momentos de máximos hidrológicos. Por tanto, la variabilidad hidrológica del arroyo en la sección estudiada, muestra un rango de algo menos de $1 \mathrm{~m}$ para el estado de bank-
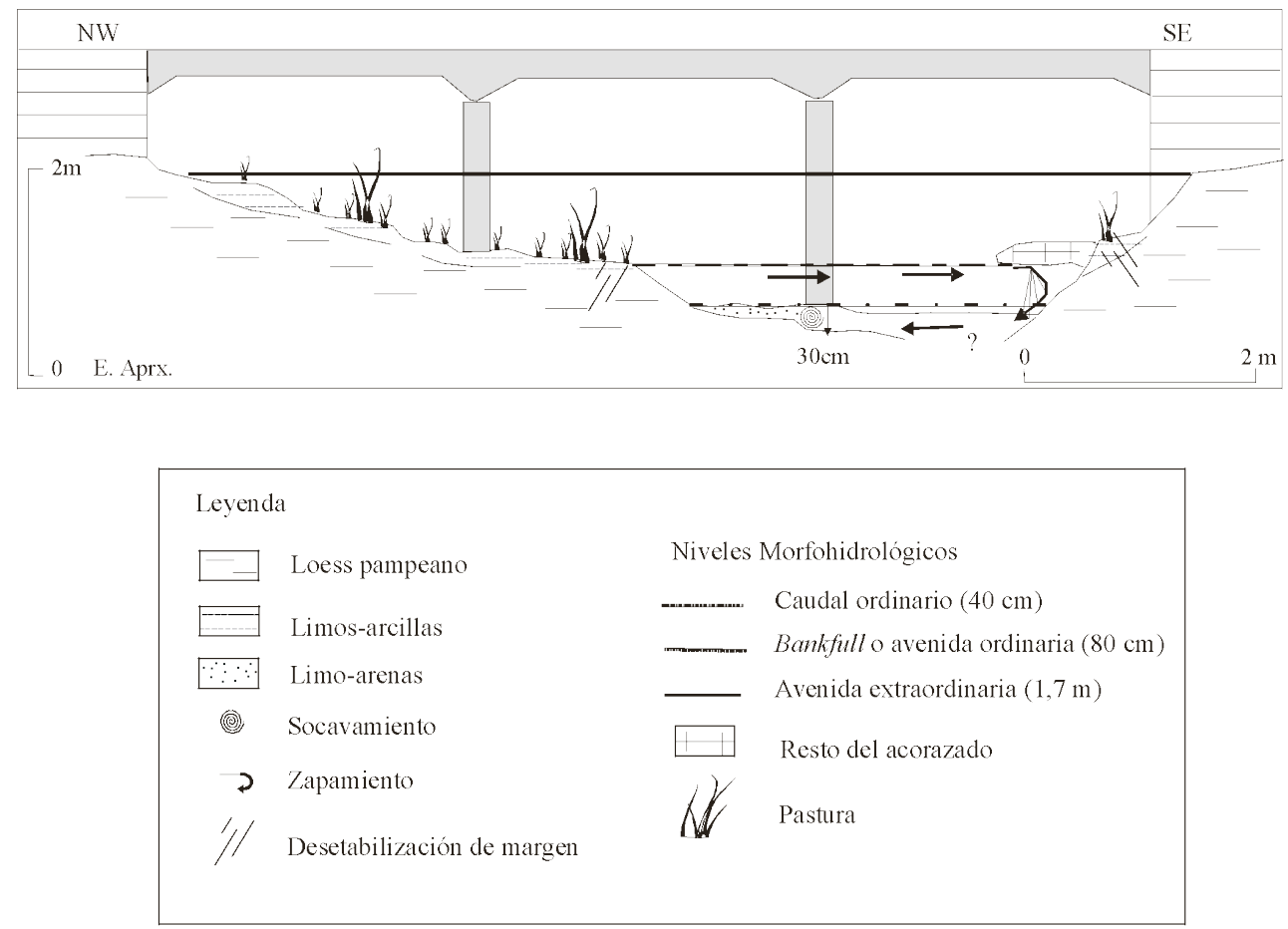

Figura 9. Transversal hidromorfológica del Arroyo Seco en la ruta nacional 3. 
full $(0,80 \mathrm{~cm})$, por encima del cual el flujo invadiría la llanura de inundación. En la zona, la máxima crecida registrada, según la marca de humedad reconocida en el puente, alcanzó una altura de aproximadamente $1,7 \mathrm{~m}$. Un ejemplo de la magnitud de la crecida que puede llegar a generar el Tercer brazo, queda reflejada en la foto 1 , en la que este colector, aguas arriba de la sección transversal, inunda el núcleo de población De la Garma (año 2002).

Desde un punto de vista hidráulico, y en la transversal de estudio, el desarrollo del flujo helicoidal en el cauce activo, trae como consecuencia la sobreexcavación y el zapamiento en la margen externa, llegando incluso a desestabilizar los taludes de la orilla; y la sedimentación en la margen interna. Esta erosión lateral por zapamiento, desmantela igualmente, lo que podría haber sido el acorazado del puente; en la actualidad, en posición marginal y exhumada. Así mismo, se identifica en el lecho un ligero socavamiento de $30 \mathrm{~cm}$, frente a la pila. Este proceso está asociado, sin duda, al tipo de pila carente de forma hidrodinámica; lo que infiere una mayor turbulencia al flujo, en bankfull. En definitiva, el balance energético infiere una cierta tendencia a la incisión en la sección planteada, al que acompaña procesos de socavamiento local en el lecho y zapamiento en taludes.

Las márgenes desprovistas, una vez más de cualquier especie de vegetación natural, están cubiertas por la pastura utilizada para la alimentación del ganado. Tan sólo sobresalen algunos ejemplares de eucaliptos y chopos blancos (Populus alba).

Por último, en el estudio morfodinámico del Arroyo Claromecó se ha llevado a cabo el análisis de dos secciones transversales al cauce, en su tramo estuarino: la primera a unos $100 \mathrm{~m}$ de la desembocadura al océano Atlántico, a la altura del puente peatonal; y la segunda, a $1 \mathrm{~km}$ de la anterior y a la altura del puente carretero que une Claromecó con Dunamar.

A escasos metros de la desembocadura, el arroyo Claromecó desarrolla un cauce ordinario de $15 \mathrm{~m}$ de anchura y $2 \mathrm{~m}$ de profundidad, limitado por las barrancas. Su morfología está definida por un lecho ligeramente plano, hidráulicamente liso, y taludes labrados sobre tosca y loess pampeano, con evidentes signos de inestabilidad. Por tanto, se configura como un cauce ancho y sinuoso en planicie de llanura, con márgenes inestables y niveles de acarcavamiento.

Asimismo, la presencia de los restos de un antiguo puente, destruido en la crecida del año 1998, aporta datos hidromorfológicos interesantes (figura 10). Por un lado, se observa, en la margen izquierda, restos del antiguo acorazado del puente, y algunas pilas en las que se evidencian distintos niveles de refuerzo, actualmente exhumados. Y por otro, se distinguen distintos niveles de humedad, que en relación con las morfologías existentes, pueden identificar los distintos niveles hidrológicos (caudal ordinario, bankfull y caudal de crecida). En este sentido el socavamiento de la base del talud se corresponde con los niveles de caudal en bankfull y en avenida; periodos en los que aumenta la capacidad erosiva del arroyo. Junto a ello, la ruptura del acorazado del puente, y la exhumación de las bases de las pilas $(0,95 \mathrm{~m})$ indican una cierta tendencia general a la incisión en el arroyo Claromecó en su tramo bajo. 

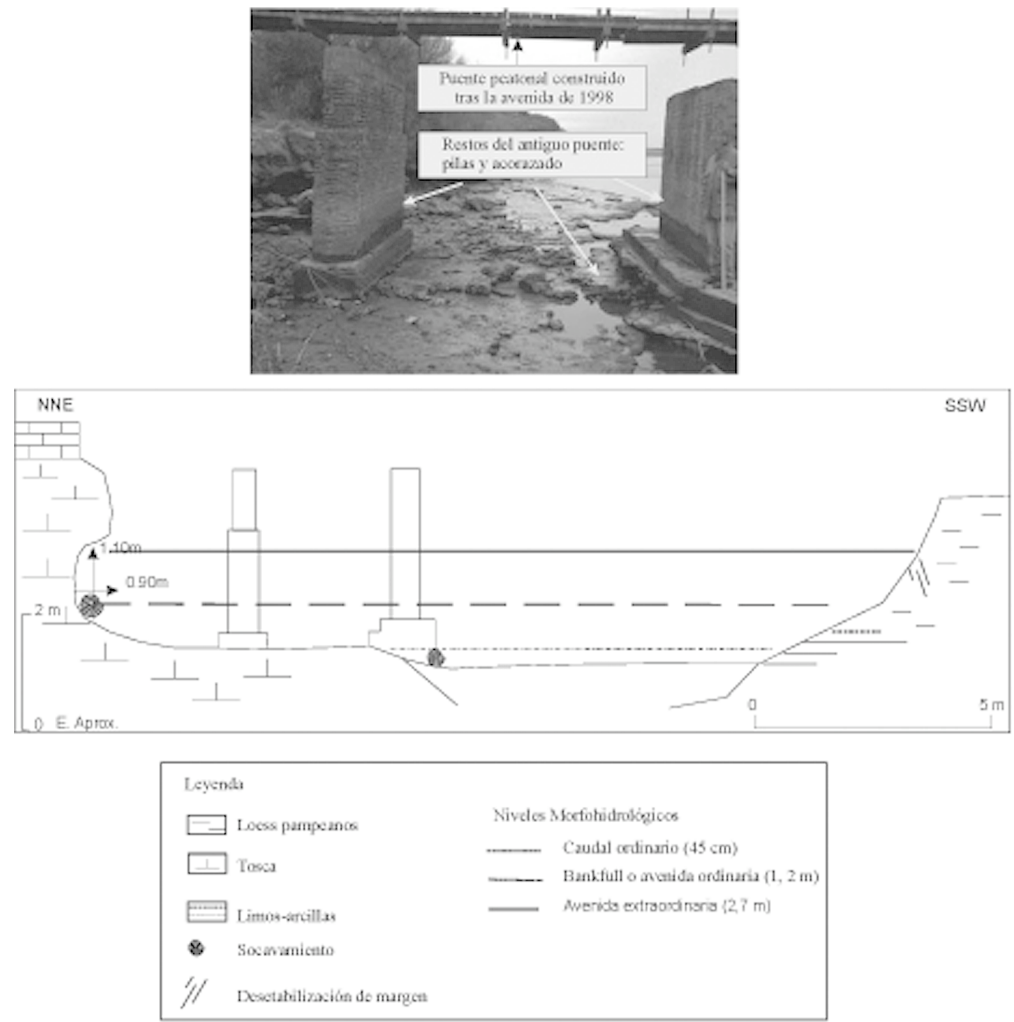

Figura 10. Transversal hidromorfológica del Arroyo Claromecó a unos 100 m de su desembocadura con el Océano Atlántico.

Por otro lado, la capacidad erosiva mostrada por el Claromecó en la crecida de 1998, a juzgar por el estado del puente, bien pudo deberse a una conjunción de fenómenos: por un lado, el nivel alcanzado por las aguas de crecida $(1,7 \mathrm{~m})$ y por otro, el tapón hidráulico que supone la influencia mareal para la normal evacuación de su caudal. Todo ello, suele aumentar la turbulencia y en consecuencia, la capacidad erosiva y destructiva de las aguas fuera de los límites del cauce ordinario.

En cuanto a la vegetación, prolifera el tamarisco (Tamarix), en una posición próxima a la línea de ribera. En condiciones naturales, esta especie, originaria de la región mediterránea, se sitúa en línea de costas, y ríos de aguas calcáreas y salobres. Fuera de su ámbito natural, se utiliza con éxito para aportar estabilidad en suelos arenosos, dado que sus raíces contribuyen a fijar el suelo. Asimismo, abunda el denominado plumero o hierba de la pampa (Cortaderia selloana), cuya posición, en la zona, define el nivel de caudal ordinario. 

Cintia Píccolo y Gerardo M. E. Perillo

Aguas arriba del anterior, a la altura del puente carretero que une Claromecó con Dunamar, se mantiene en unos casos y clarifican, en otros, las características hidromorfológicas descritas con anterioridad. Así el caudal ordinario se mide en 0,70 m, el límite de cauce ordinario en 1,2 m y el caudal de crecida en 1,6 m. En este sentido, los niveles alcanzados por la lámina de agua, en cada momento, están relacionados, en su mayoría, con los evidentes signos de inestabilidad en las márgenes (foto 2).

De esta manera, los pequeños deslizamientos detectados en los taludes del cauce ordinario, estarían vinculados a los procesos de zapamiento, que el flujo de máxima energía acomete en estado de bankfull. Un signo más de este proceso es el nivel de exhumación de las raíces de la vegetación localizada en la margen izquierda, que anticipa su desplome en vertical. Por otro lado, los regueros detectados en las barrancas, estarían asociados a la circulación del agua fuera de los límites del cauce ordinario. Por último, y en marea baja, se llegan a identificar unos niveles de playa en ambas márgenes, por debajo del límite de caudal ordinario.

Por último, la vegetación sigue siendo, en su mayoría, alóctona; siendo este hecho, especialmente llamativo en este sector. Así, especies como el tamarisco, la retama, el pino e incluso el abeto, están representadas en este sector, dando a las márgenes un aspecto muy alejado del típico paisaje fluvial pampeano.

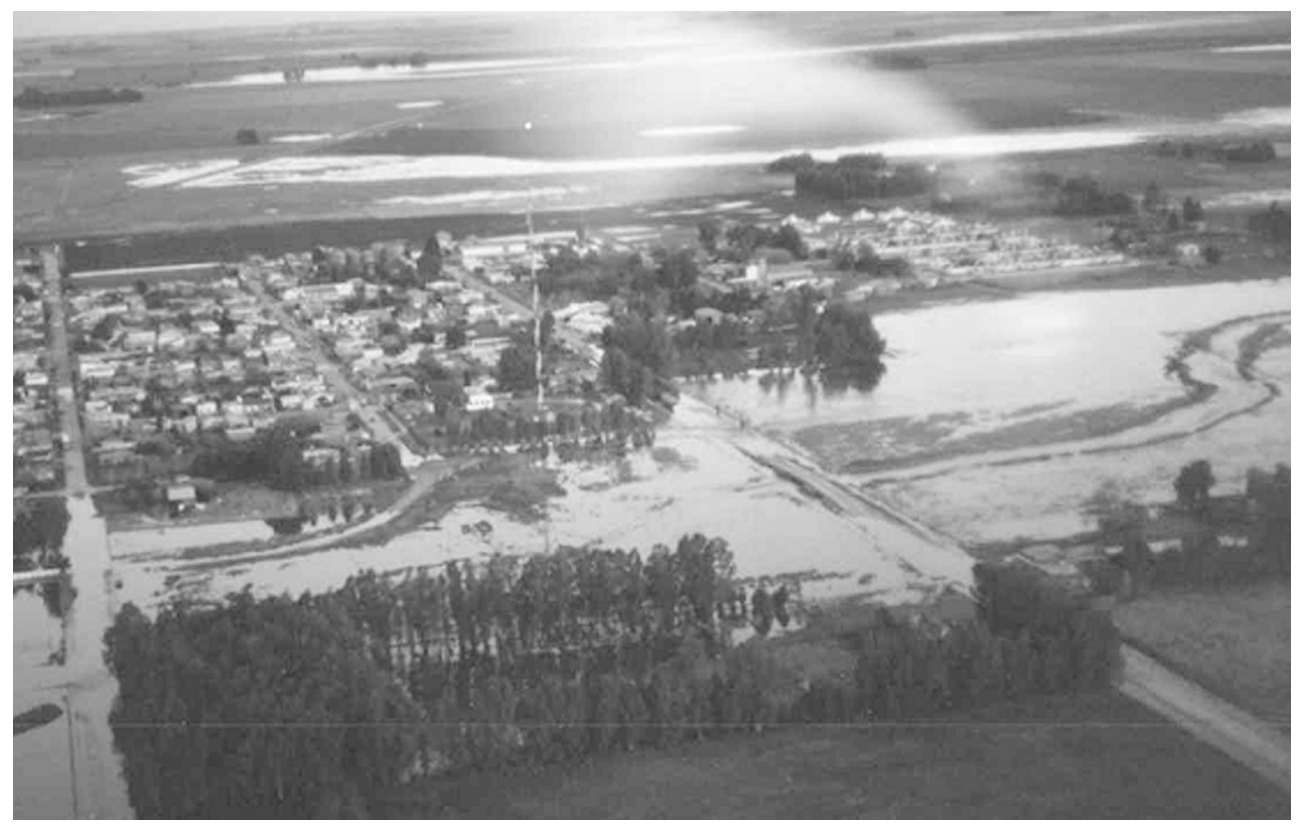

Foto 1. 


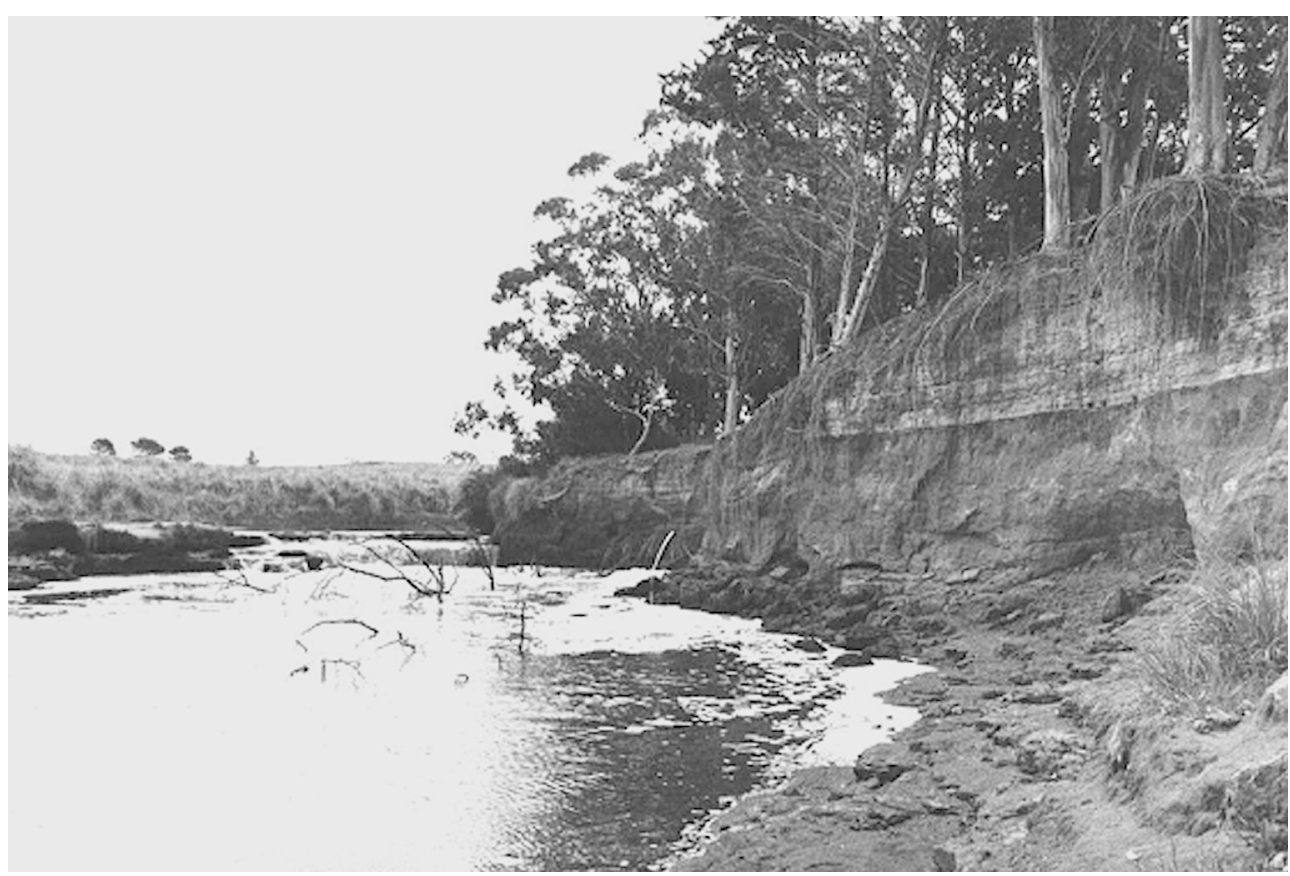

Foto 2 .

\section{Discusión}

La variabilidad hidrológica del arroyo Claromecó para la serie 1999-2002, queda englobada en lo que Pardé (1955) definió como régimen Pluvial Oceánico. Su particularidad queda definida por la existencia de un solo máximo, desde octubre a diciembre, cuyo punto más álgido se da en diciembre, con un coeficiente de 1,6. Y un mínimo poco acusado, desde enero a septiembre, con valores de coeficientes de 0,6. Así mismo, se aprecia una ligera recuperación de la curva en los meses de abril y mayo, sin llegar a superar el valor modular. Este comportamiento está algo alejado de lo que definió Pardé para un pluvial oceánico, a saber: dos máximos en diciembre y febrero, separados por un leve descenso en enero; y un mínimo por debajo de 0.5 durante los meses desde junio a septiembre. La diferencia, en el Claromecó, radica principalmente, en la existencia de un caudal de base procedente del acuífero, que le aporta hasta un 36\% de la descarga (Carbone et al., 2006).

El análisis de los parámetros que definen el comportamiento hidrológico de la cuenca, aportan datos que avalan igualmente, la retención de agua en la cuenca del Claromecó. Bien sea por filtración y percolación a acuíferos, bien por retención 

Cintia Píccolo y Gerardo M. E. Perillo

superficial de los sistemas lacustres. Así, con una entrada en la cuenca del Claromecó, de más de $800 \mathrm{~mm}$, el arroyo tan sólo aporta al mar $31.1 \mathrm{Hm} 3 /$ año; generando tan sólo $0.331 / \mathrm{km}^{2}$. Pero sin duda el parámetro que mejor refleja este desfase entre, entradas y salidas de agua en el sistema, es el coeficiente de escorrentía. Sólo el 1,16\% del agua que entra en la cuenca del Claromecó sale por la vía del escurrimiento superficial, directo al mar.

Este comportamiento es precisamente lo que invalida la aplicación de las ecuaciones empíricas de Grunsky y Turc, en la obtención de caudales teóricos en el Claromecó, al contrario de lo que sucede en otros sistemas fluviales (Sandoval, 2000; Sánchez, 2001). En el caso de la ecuación de Grunsky, aún cuando aporta buenos datos en la obtención del caudal medio anual teórico, para sistemas fluviales costeros con régimen de alimentación pluvial (Sánchez, 2001), no se considera válido en el caso del Claromecó. Considerado el Claromecó cono un sistema fluvial de alimentación estrictamente pluvial, las características hidrológicas de su cuenca, definidas con anterioridad, determinan la existencia de un flujo subterráneo muy potente que en ningún caso, es contemplado en la ecuación de Grunsky; por lo que los datos teóricos estimados distan bastante de los reales. En el caso de la ecuación de Turc, los trabajos realizados por otros autores (Sandoval, 2000 cfr. Benítez, 1998) ya estimaban desviaciones importantes en los caudales, en aquellas cuencas con características peculiares, como podía ser presencia de nieve o fuerte insolación, entre otras. En este caso, las características hidrológicas de la cuenca del Claromecó pudiera entenderse, por tanto, como una peculiaridad que determina la escasa correlación detectada entre caudales reales y los estimados.

De esa manera, la escasa topografía, la existencia de suelos porosos, un alto hidromorfismo, y un deficiente drenaje superficial, permite que el agua quede retenida en la cuenca por colmatación del sistema lacustre, o por infiltración y percolación hacia los acuíferos.

Por otro lado, si atendemos al comportamiento hidrológico del suelo, se observa una buena correlación entre el régimen del arroyo y el balance hídrico de su cuenca. Así, el inicio del año hidrológico se vincula con la recuperación del caudal, tras un periodo con un caudal por debajo del valor modular. Dicha recarga edáfica que se amplía hasta agosto, se manifiesta en una recuperación general de la curva de caudal. Así mismo, el caudal supera el valor modular en el momento, en el que el suelo alcanza su capacidad de campo y se inicia la escorrentía. En ese periodo, que dura desde agosto a noviembre, el río registra su máximo caudal. La excepción la encontramos en el mes de diciembre. Según los datos aportados por el balance, en diciembre ya se habría iniciado el periodo de déficit hídrico; y sin embargo, en este mes, es cuando el Claromecó alcanza su máximo caudal. Esta situación sólo se mantiene durante este mes, ya que los meses siguientes, enero y febrero reflejan un descenso en la curva de caudal, más acorde con el periodo de déficit hídrico. A pesar de ello, durante el periodo de déficit hídrico, el suelo sigue manteniendo un remanente de $100 \mathrm{~mm}$. Por su parte, el Claromecó mantiene un nivel de caudal medio por encima 
de $0,60 \mathrm{~m}^{3} / \mathrm{s}$. Por tanto, en este periodo analizado, ni el suelo pierde la totalidad del agua ni el arroyo experimenta un marcado estiaje.

De otro lado, el estudio hidromorfológico de determinadas secciones fluviales aportan datos a tener en cuenta: en primer lugar, se detecta, una vez más, la escasa irregularidad que presenta el Claromecó en su régimen. Este hecho se desprende del rango de variabilidad entre el caudal ordinario y en bankfull, nunca superior a $1,5 \mathrm{~m}$; y entre bankfull y crecida extraordinaria, inferior a $1 \mathrm{~m}$. Y en segundo lugar, queda patente la relación existente entre la configuración morfológica del cauce y la variabilidad hidrológica descrita para cada sección fluvial estudiada. En este sentido, los socavamiento laterales detectados en los taludes del cauce ordinario están vinculados, por lo general, al ataque erosivo del flujo de máxima energía en estado de bankfull. Este hecho, junto con la naturaleza limo-arcillosa de los taludes y el tipo de vegetación, determina que las márgenes presenten cierta inestabilidad. Por su parte, los socavamientos locales localizados en los lechos, suelen estar asociados a la turbulencia que introducen la forma de las pilas de los puentes.

Por otro lado, los trabajos de canalización del Claromecó, así como de los tramos urbanos y suburbanos de sus afluentes, modifican las características morfodinámicas del sistema. La ampliación y profundización de cauces, así como la rectificación de los trazados, está generando, especialmente en el tramo principal del Claromecó, una tendencia a la incisión. Así lo demuestran, al menos, la exhumación de, aproximadamente, $1 \mathrm{~m}$ de las bases de las pilas, la altura de las barrancas (de hasta $6 \mathrm{~m}$ ), y la vegetación; cuya posición de ladera, anticipa su desplome vertical, por zapamiento.

A todo ello, se le une la práctica desaparición de la vegetación natural de ribera en la cuenca del Claromecó y su sustitución por otro tipo de especies alóctonas; tales como el eucalipto, el pino, la retama, etc. Éstas, lejos de aportar estabilidad a las márgenes, introducen además un cambio en el paisaje fluvial típico de la Pampa.

\section{Conclusiones}

Desde un punto de vista hidrológico, la cuenca del arroyo Claromecó es una cuenca deficitaria, puesto que buena parte del agua que entra en el sistema no sale por la vía del escurrimiento superficial. En esta cuenca predominan los procesos de infiltración y percolación, tal y como se deriva de los datos obtenidos en el balance hídrico de la cuenca media. Este hecho, junto con el desfase temporal descrito entre la estacionalidad de la precipitación y del caudal determina, que se haya desestimado la aplicación de los modelos teóricos de Grunsky y Turc para la obtención de caudales teóricos en esta cuenca.

Con ello, el arroyo Claromecó, para los años 1999-2002 presenta un régimen pluvial oceánico matizado, con un máximo en diciembre y un estiaje poco acusado, asociado a la descarga del flujo de base. El comportamiento hidrológico de su cuenca, representado por un escaso módulo, una débil irregularidad estacional, valores de 
aportación y caudal específico modestos, y un pequeño coeficiente de escorrentía, refleja la retención del caudal en la cuenca del Claromecó. Ésta puede estar asociada al sistema lacustre desarrollado, principalmente, en la cuenca alta del arroyo; o a los procesos de infiltración y percolación que alimenta los acuíferos.

Así mismo, las actividades antrópicas acometidas en la red fluvial del Claromecó, están infiriendo cambios en la dinámica fluvial, reactivándose los procesos de zapamiento de márgenes, socavamiento de lechos e incisión fluvial. En consecuencia, se detecta una cierta inestabilidad en las márgenes.

Por último, la vegetación de ribera es en su mayoría alóctona y responde a una reforestación de márgenes. Este hecho, no sólo determina un cambio en el paisaje fluvial sino que no asegura la estabilidad de los taludes.

\section{Agradecimientos}

Este trabajo se lleva a cabo en el contexto del Programa Nacional de Ayudas para la Movilidad (Ref. PR2007-0397), financiado por el Ministerio de Educación y Ciencia del Estado español.

\section{Bibliografía}

Carbone, M.E. y Píccolo, M.C. (2002) Human and physical characteristics of the Claromecó river basin, Argentina. Papeles de Geografia, 35: 27-35.

Carbone, M.E. (2004) Hidrografía del Arroyo Claromecó. Tesis doctoral inédita, Universidad Nacional del Sur, Bahía Blanca, Buenos Aires.

Carbone, M.E, Piccolo M.C. y Perillo G.M.E. (2006) Comportamiento hidrológico del arroyo Claromeco, Argentina. Investigaciones Geográficas, 39: 179-193.

Carling, P.A. (1988) The concept of dominant discharge applied to two gravel-bed streams in relation to channel stability thresholds, Earth Surface Processes, 13: 355-367.

Gregory, K. y Walling, D. (1973) Drainage basin form and process. London, Arnold.

Henderson, F.M. (1961) Stability of alluvial channels. J. Hydraulic Div., 87: 109-138.

Morisawa, J.M. (1973) Fluvial Geomorphology. London, Allen and Unwin.

Pagney, P. (1982) La climatología. Barcelona, Oikos-Tau.

Pardé, M. (1955) Fleuves et rivières. Paris, Armand Colin.

Pleus, A.E. y D. Schuett-Hames (1998) $T F W$ monitoring program methods manual for the reference point survey. Washington State Dept. of Natural Resources under the Timber, Fish, and Wildlife Agreement. TFW-AM9-98-002.

Sánchez Aravena, F. (2001): Análisis y evolución comparative de siete modelos de precipitación-escorrentía (Budyko, Coutagne, Grunsky, Peñuelas, Pizarro, Turc y TurcPike) en la cuenca del río Malleco, IX Región. 75 pp. Tesis. Universidad de Talca. Inédita.

Sandoval, C. (2000) Análisis comparativo de los modelos precipitación-escorrentía de 
Grunsky, Peñuelas, Coutagne y Turc en la cuenca del río Achibueno y en la cuenca del río Purapel, VII Región. Tesis inédita.

Schumm, S.A. y Lichty, R.W. (1965) Time, space and causality en geomorphology. American Journal of Science, 263: 110119.

Schumm, S.A. (1960) The shape of alluvial channels in relation to sediment type. US. Geol. Surv. Pap, 352-B, 30.

Schumm, S.A. (1977) The fluvial System. Chichester, Wiley-Interscience.

Vélez, M. y Vélez, J. (2002) Relación precipitación-escorrentía. Universidad Nacional de Colombia, Facultad de Minas. Unidad de Hidráulica

$<$ http//poseidon.unalmed.edu.co/materia/ hidrologia.html>

Williams, P.G. (1978) Bankfull discharge of rivers. Water Resources Research, 14 (6): 1141-1154.

Wolman, M.G. y Leopold L.B. (1957) River flood plains: some observation on their formation. U.S. Geol. Surv. Prof. Pap., 282, 87-109. 